\section{Heinz G. Endres \\ Gabriele Böwing Hans-Christoph Diener \\ Stefan Lange \\ Christoph Maier \\ Albrecht Molsberger \\ Michael Zenz \\ Andrew J. Vickers \\ Martin Tegenthoff}

\section{Received: 31 July 2007}

Accepted in revised form: 25 September 2007

Published online: 25 October 2007

H.G. Endres ( $ه$ )

Department of Medical Informatics,

Statistics and Epidemiology, Ruhr

University Bochum, Universitaetsstr. 150,

D-44801 Bochum, Germany

e-mail: heinz.endres@ ruhr-uni-bochum.de

Tel.: +49-234-3226564

Fax: +49-234-3206564

G. Böwing • A. Molsberger

Acupuncture Research Group, Kasernenstr.

1b, D-40213 Duesseldorf, Germany

H.-C. Diener

Department of Neurology, University Essen,

Hufelandstrasse 55, D-45122 Essen, Germany

S. Lange

Institute for Quality and Efficiency in

Health Care, Dillenburger Str. 27, D-51105

Cologne, Germany

C. Maier

Department of Pain Management, BG-

Kliniken Bergmannsheil, Ruhr University

Bochum, D-44789 Bochum, Germany

M. Zenz

Department of Anaesthesiology,

BG-Kliniken Bergmannsheil,

Ruhr University Bochum, D-44789

Bochum, Germany

\section{A.J. Vickers}

Department of Medicine and Department of Epidemiology and Biostatistics,

Memorial Sloan-Kettering Cancer Center,

New York, NY 10021, USA

M. Tegenthoff

Department of Neurology, BG-Kliniken

Bergmannsheil, Ruhr University Bochum,

D-44789 Bochum, Germany

\title{
Acupuncture for tension-type headache: a multicentre, sham-controlled, patient- and observer-blinded, randomised trial
}

\begin{abstract}
Acupuncture treatment is frequently sought for tension-type headache (TTH), but there is conflicting evidence as to its effectiveness. This randomised, controlled, multicentre, patient- and observerblinded trial was carried out in 122 outpatient practices in Germany on 409 patients with TTH, defined as $\geq 10$ headache days per month of which $\leq 1$ included migraine symptoms. Interventions were verum acupuncture according to the practice of traditional Chinese medicine or sham acupuncture consist-

difference $12 \%, 95 \%$ CI: $2 \%-21 \%$; $p=0.024)$. The relative risk on the primary and secondary response criterion was very similar ( 0.8); the difference in statistical significance may be due to differences in event rate. TTH improves after acupuncture treatment. However, the degree to which treatment benefits depend on psychological compared to physiological effects and the degree to which any physiological effects depend on needle placement and insertion depth are unclear.
\end{abstract} ing of superficial needling at nonacupuncture points. Acupuncture was administered by physicians with specialist acupuncture training. Ten 30-min sessions were given over a six-week period, with additional sessions available for partial response. Response was defined as $>50 \%$ reduction in headache days/month at six months and no use of excluded concomitant medication or other therapies. In the intent-to-treat analysis (all 409 patients), 33\% of verum patients and $27 \%$ of sham controls $(p=0.18)$ were classed as responders. Verum was superior to sham for most secondary endpoints, including headache days (1.8 fewer; 95\% CI 0.6, 3.0; $p=0.004)$ and the International Headache Society response criterion $(66 \%$ vs. $55 \%$ response, risk
Keywords Episodic tension-type headache . Chronic tension-type headache $\cdot$ Verum acupuncture . Sham acupuncture $\cdot$ Randomised controlled trial 


\section{Introduction}

Tension-type headache (TTH) is a bilateral diffuse headache associated with a sensation of pressure, but without significant autonomic disturbances. The International Headache Society (IHS) differentiates episodic from chronic headache using the criterion of less than or more than 15 headache days per month [1]. Epidemiological studies show a one-year prevalence of $30 \%-60 \%$ for episodic TTH and 2\%-3\% for chronic TTH [2-4]. Many TTH patients seek acupuncture treatment: it has been estimated that, each week, $10 \%$ of general practitioners in England either refer patients to acupuncture or perform it themselves [5], and chronic headache is one of the most commonly treated conditions [6].

Nonetheless, the effectiveness of acupuncture remains controversial [7,8]. In the German acupuncture trials (GERAC), we investigated the effects on headache frequency of acupuncture based on principles of traditional Chinese medicine (verum acupuncture) vs. superficial needling without needle stimulation at non-acupuncture points (sham acupuncture) in patients with episodic or chronic TTH.

\section{Methods}

Study design and study sites

The design of this trial has been described previously [9]. In brief, GERAC tension-type headache was a multicentre, randomised, patient- and observer-blinded trial comparing verum and sham acupuncture, performed in 122 family physician practices in 11 federal states in Germany. All physicians had at least $140 \mathrm{~h}$ of acupuncture training: $43 \%$ had received basic training (mean $208 \mathrm{~h}$ ) and 57\% had advanced training (mean $398 \mathrm{~h}$ ). The physicians had practised acupuncture for a median of 8.5 years (range 2-36 years). All took part in a one-day training emphasising acupuncture modalities and study design. Each patient in the study was seen by a single acupuncturist. The study complied with the Helsinki Declaration and the Guideline for Good Clinical Practice. It was approved by the ethics committees of all 12 German state medical associations involved in the study and by the ethics committee of the principal investigators' site.

\section{Randomisation}

Randomisation was performed centrally by telephone using a secure, password-protected database. Block sizes were of variable length unknown to trial physicians. This ensured full allocation concealment: allocation could not be guessed before a patient was unambiguously registered on trial or altered afterwards. Independent clinical monitors regularly visited all study sites. All study participants provided written, informed consent and the study was approved by the ethics committees of all 12 German state medical associations involved in the study.

Patients

Most patients were recruited through advertisements in local newspapers, and reports on radio and television; a minority spontaneously sought out a trial physician. German-speaking patients aged 18-65 with a diagnosis of episodic or chronic TTH were eligible. We used IHS diagnostic criteria, which establish, in particular, the minimum frequency and minimum duration for the occurrence of headache episodes [1]: patients must have at least 10 headache days per four weeks where a headache day is defined as a day on which headache lasts at least $4 \mathrm{~h}$ or when analgesics are taken for headache pain, in which case the headache pains could persist for less than four hours. The principle exclusion criteria were as follows: duration of symptoms less than six months; >1 migraine headache day per four weeks; medication overuse headache or other secondary headaches; other severe pain disorders; use of analgesics other than aspirin, acetaminophen and NSAIDs; any change in pain medication during the previous 8 weeks; TTH prophylaxis during the previous 12 months; any acupuncture treatment during the previous 12 months; any prior use of acupuncture for headache (to maximise blinding).

\section{Interventions}

The trial initially included an arm receiving treatment with amitriptyline, currently the most widely accepted prophylaxis for TTHs [10]. However, poor early accrual was ascribed to patient unwillingness to receive antidepressant medication and, on the recommendation of the independent data and safety monitoring committee, this arm was dropped after one year (March 2003).

As acupuncture recommendations are controversial [11], rules for point selection and Chinese diagnosis were established on the basis of international literature and a consensus process with German and international experts. The exact mode of acupuncture is published elsewhere [12]. In brief, verum and sham points were selected from prescribed lists. Verum treatment consisted of fixed points used in all patients with additional points chosen individually by the physicians on the basis of traditional Chinese medicine diagnosis, including tongue diagnosis. Needles were inserted $2-30 \mathrm{~mm}$ and manually stimulated to achieve $D e Q i$, a radiating sensation considered to be indicative of effective needling. Neither electrical stimulation nor moxibustion were allowed. Patients were reassessed at each visit, and chosen acupuncture points were modified whenever clinically 
indicated. Sham acupuncture avoided all known verum points or meridians for needling; moreover, no points on the head could be used in the sham group. Needles were inserted superficially (1-3 $\mathrm{mm}$ ) and were not stimulated, so as to avoid De $Q i$ in the sham group. The number (10-25) and type of needles (sterile, singleuse needles, coated, $0.25-0.30 \mathrm{~mm}$ thick, 25-40 mm long), and number (10-15), length (30 $\mathrm{min})$ and frequency (2/week) of treatment sessions were the same in each group. Investigators were instructed to treat patients in each group identically in all ways other than the placement of needles. During informed consent, patients were informed that they would receive either a "traditional Chinese form of acupuncture" (verum) or a "form of acupuncture developed especially for this study" (sham). In keeping with the recommendations of international acupuncture experts, all patients could receive an additional 5 sessions if they experienced a reduction in headache days/28 days of at least $20 \%$ but no more than $50 \%$. This was assessed in a telephone interview after 10 sessions (Fig. 1), although both interviewers and patients were blind to the criterion for additional treatment. During the study, patients were allowed to take only one of their pre-baseline oral headache analgesics. They were not allowed to change this analgesic.

Outcome measures

All patients completed daily diaries of headaches and medication use every day from four weeks before to six months after randomisation. Other endpoints (such as the SF-12) were obtained by blinded telephone interview at the end of the four-week baseline phase, and at 6 weeks, 3 months and 6 months after randomisation (Fig. 1). The primary outcome, "response", was defined as $>50 \%$ reduction in number of headache days per four weeks from baseline to 6 months. If one of the following criteria applied, however, the patients were characterised as non-responders, regardless of whether a reduction of $>50 \%$ had been achieved or not: patient unblinding, excluded concomitant treatments (pharmacological or non pharmacological), injections (except vaccinations, insulin, heparin), wrong acupuncture treatment (verum acupuncture instead of sham acupuncture for 3 patients), median number of needles more or fewer than the permitted 10-25 needles per session, treatment cessation (independent of when it occurred) or any change of analgesics. Secondary outcome measures include the Von Korff chronic pain grade scale in a modified 3-month version [13-15]; the German version of the SF-12 (12-Item Short-Form Health Survey) for health-related quality of life [16]; a patient global assessment of therapy effectiveness on a scale of 1 (very good) to 6 (fail) [17] and medication use.

Quality of acupuncture treatment was assessed by average time (minutes) investigators spent with patients and average length (minutes) of sessions, as estimated by patients in the six week interview, and by total treatment period in days, number of sessions completed and number of needles used per session, as documented in the case report forms.

Patient blinding was assessed at the six-month interview by asking patients whether their physician had informed them of their allocation, and, if not, which treatment they believed they had received and how certain they were of their response.

Statistical analysis

On the basis of a Cochrane review [8], we anticipated that $60 \%$ of verum patients would experience a $>50 \%$ reduction in headache days compared to $40 \%$ of the control group. We assumed that $30 \%$ of patients would meet a criterion (such as

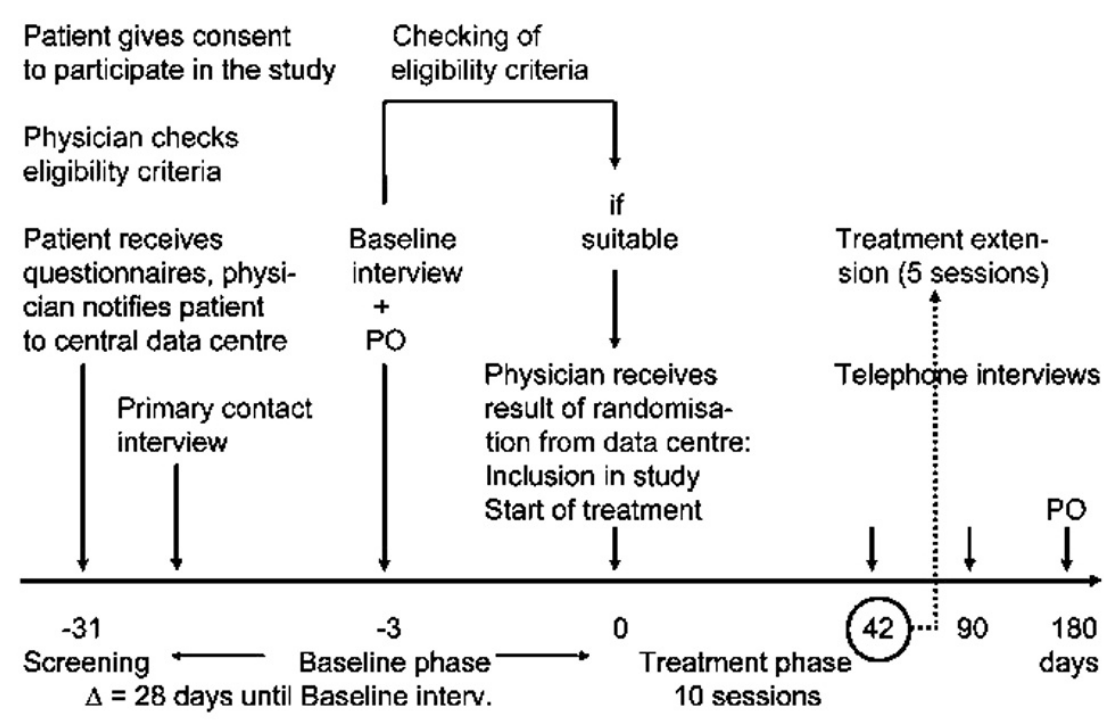

Fig. 1 Study design for GERAC tension-type headache study. PO, primary outcome measure. Modified version of a figure published in [9], figure 1 on page 202. Written permission for reproduction granted 
change in medication) entailing that they would be classified as a non-responder, yielding a final response rate of $42 \%$ for verum and $28 \%$ for sham. We sought 315 patients per group, for a power of $95 \%$. The independent data and safety monitoring committee recommended stopping the study early due to accrual difficulties. Our sample size of 409 patients gives a power of $84 \%$ to detect our hypothesised difference in proportions.

All analyses were conducted on the intention-to-treat principle, with patients analysed according to allocated treatment group, irrespective of treatment received. Missing data were not replaced: for the primary analysis, the 11 patients, 5 verum and 6 sham, who did not take part in a six-month interview were treated as non responders. These 11 patients included the 6 patients who refused to participate immediately after randomisation plus another 5 patients who refused to continue during or after the acupuncture treatment. We used Fisher's exact test for the statistical analysis of the primary outcome measure of response. Secondary outcomes were compared by linear regression using baseline score as a covariate (ANCOVA) or Fisher's exact test. Analyses were conducted using SAS 9.1.3. (SAS, Cary, NC).

\section{Results}

Between April 2002 and July 2005, 824 patients with headache were screened, and 413 were randomised, 4 to the amitriptyline group (abandoned March 2003), 209 to the verum group and 200 to the sham group. Participant flow is shown in Fig. 2. The main reasons for non randomisation were headaches other than TTH $(n=121),<10$ headache days/28 days $(n=93),>1$ migraine day/28 days $(n=67)$ and previous acupuncture for headache $(n=27)$. Baseline demographic and clinical characteristics were similar between groups (Table 1). Compliance was excellent: only six patients (1 verum, 5 sham) did not receive planned treatment. Blinding appears to have been maintained: approximately half of the patients answered correctly when asked which acupuncture treatment they thought they had received (correct response: verum $42 \%$, sham $48 \% ; p=0.3$ ) and there was no significant association between responses concerning treatment allocation and outcome $(p=0.15)$. A small number of patients (22 in each group) reported being unblinded by their physician, although only half did indeed correctly identify their allocation (10 sham, 13 verum).

Verum group patients were treated with a mean of 16.5 (SD 5.2) needles, sham group patients with a mean of 14.6 (SD 4.8) needles (Table 2). The difference was statistically significant $(p<0.001)$ but small. Patients' estimate of mean session length was $32.5 \mathrm{~min}$ (SD 7.5) for verum and $32.2 \mathrm{~min}$ (SD 8.8) for sham treatment $(p=0.718)$, and the estimate of mean time the physician spent with them was $8.8 \mathrm{~min}$ (SD 5.4) for the verum and 7.8 min (SD 4.8) for the sham group $(p=0.045)$. Thirtyone verum patients (15\%) and 33 sham patients $(17 \%)$ received an extension of five additional acupuncture sessions. There were no between-group differences in the length of acupuncture sessions or the time physicians spent with patients.

Fig. 3 shows individual patient data from the trial. At 6 months, 68 of 209 (33\%) verum and 53 of 200 (27\%) sham patients were classified as responders (absolute risk difference between both groups $6 \%$; 95\% CI -3\%, 15\%; $p=0.18$ ). Other pain and quality of life endpoints are

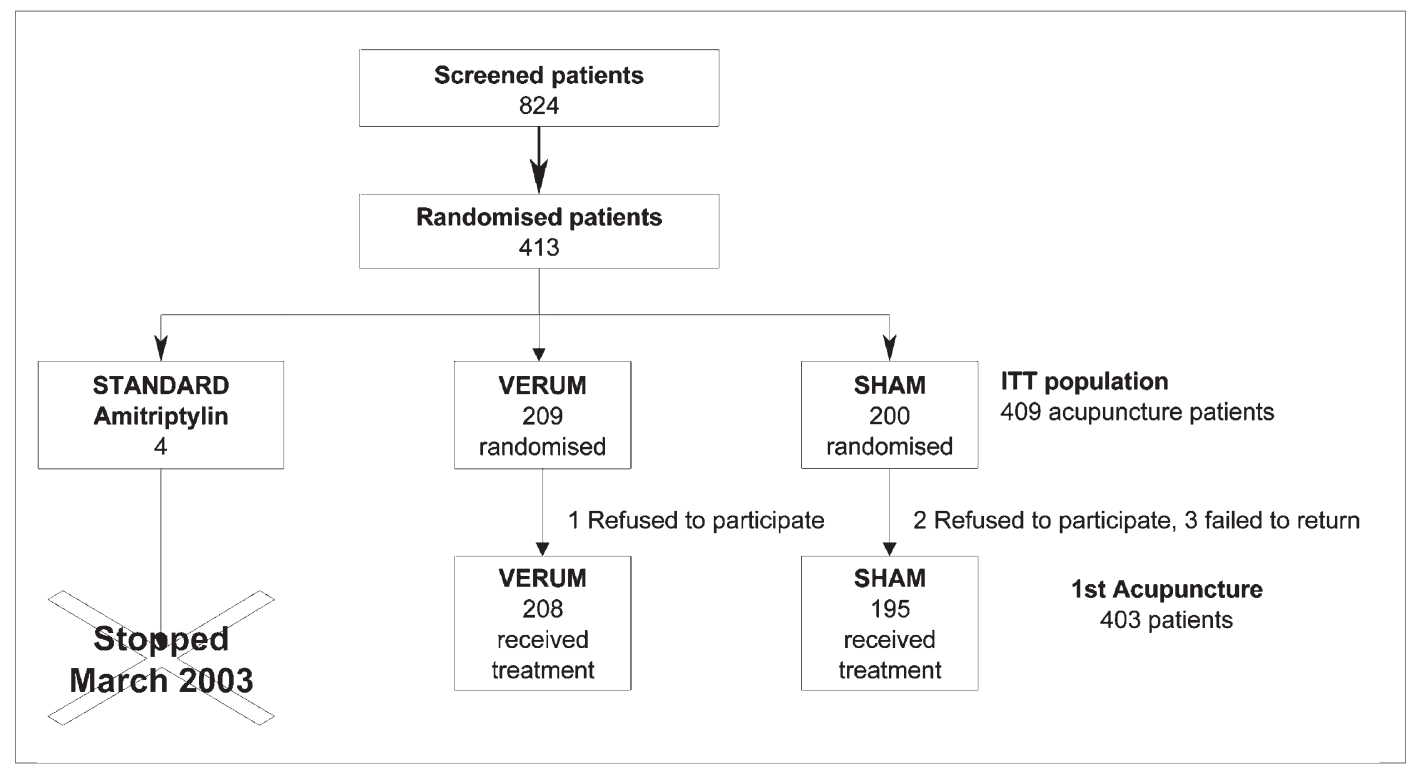

Fig. 2 Participant flow 
shown in Table 3 . Headache scores decrease rapidly to approximately half of baseline levels within 6 weeks of the start of treatment, and remain low to the 6-month follow-up. There are significant differences between groups for headache days $(p=0.002)$, global assessment $(p=0.009)$ and treatment success $(p=0.002)$. Pain intensity and physical health are superior in the acupuncture group, although differences do not reach statistical significance. Perhaps most interesting, however, is the comparison of responder rates using only the traditional IHS definition of $>50 \%$ decrease in headache days. Using this definition, at 6 months 135 of 204 (66\%) verum patients and 106 of 194 (55\%) sham patients were classified as responders (absolute risk difference 12\%; 95\% CI 2\%, $21 \% ; p=0.024)$. Table 4 shows medication use data: there are few differences between groups.

The clear and obvious difference between the results of the primary and secondary analyses led us to investigate the responder data in more detail (see Table 5). In particular, we noted a high rate of patients using non-permitted concomitant therapies, in many cases changing from one type of medication to another. This led to a large number of patients in the verum group being classified as "non-responders", regardless of the actual reduction in headache days.

We also noticed that a chance imbalance between groups at baseline as to medication use may have affected our findings. As a secondary post hoc analysis, we analysed binary endpoints by logistic regression, using baseline status as a covariate. However, differences between groups remained non-significant in all analyses. Table 6 presents an overview of all the data regarding the course of the study.

Of the ten serious adverse events (SAEs) reported, nine were classified as unrelated to the treatment; one severe headache was classified as possibly triggered by sham acupuncture. The number of SAEs corresponds to the statistically expected frequency [18].

\section{Discussion}

Both true and sham acupuncture led to persisting, clinically relevant improvements in outcome. Despite a longstanding history of TTH (mean 11.5 years), $50 \%-65 \%$ of all patients had a $>50 \%$ reduction in headache days $/ 28$ days. This cannot be explained by a selection bias, as the inclusion criteria ensured both that only patients with a long previous history of recurring tension-type headaches could take part and that no patient has previous experience of acupuncture for headaches.

Differences between groups are more difficult to inter-
Table 1 Demographic and clinical characteristics at baseline ${ }^{\mathrm{a}}$

\begin{tabular}{lll}
\hline Demographics & $\begin{array}{l}\text { Verum group } \\
n=209\end{array}$ & $\begin{array}{l}\text { Sham group } \\
n=200\end{array}$ \\
\hline Age at entry (years) & $39.2(11.4)$ & $38.9(12.2)$ \\
& $38(30-47)$ & $38(29-48)$ \\
Women & $163(78 \%)$ & $158(79 \%)$ \\
BMI in kg/m ${ }^{2}$ & $24(21-27)$ & $24(22-26)$ \\
Duration of TTH (years) & $11.2(10.3)$ & $11.7(10.7)$ \\
& $7.3(4.1-15.4)$ & $8.7(3.1-18.3)$ \\
TTH days per 4 weeks & $14(12-18)$ & $14(12-19)$ \\
Episodic headache & $116(56 \%)$ & $106(53 \%)$ \\
(<15 days per 4 weeks) & & \\
Chronic headache & $93(44 \%)$ & $94(47 \%)$ \\
$(\geq 15$ days per 4 weeks) & & \\
\hline
\end{tabular}

${ }^{\mathrm{a}}$ Data are given as mean (SD), median (interquartile range) or number (\%)

Table 2 Acupuncture therapy before extension interview (ITT population)

\begin{tabular}{|c|c|c|c|c|}
\hline CRF data & $\begin{array}{l}\text { Verum } \\
(n=204)\end{array}$ & $\begin{array}{l}\text { Sham } \\
(n=192)\end{array}$ & $\begin{array}{l}\text { Total } \\
(n=396)\end{array}$ & $p$-value \\
\hline \multicolumn{5}{|c|}{ Number of treatment sessions } \\
\hline$n$ & 204 & 192 & 396 & \multirow{4}{*}{0.351} \\
\hline Mean & 9.7 & 9.5 & 9.6 & \\
\hline SD & 1.5 & 1.6 & 1.5 & \\
\hline Missing & 0 & 0 & 0 & \\
\hline \multicolumn{5}{|c|}{ Number of needles per session } \\
\hline$n$ & 204 & 191 & 395 & \multirow{4}{*}{$<0.001$} \\
\hline Mean & 16.5 & 14.6 & 15.6 & \\
\hline $\mathrm{SD}$ & 5.2 & 4.8 & 5.1 & \\
\hline Missing & 0 & 1 & 1 & \\
\hline \multicolumn{5}{|c|}{ Treatment period (days) } \\
\hline$n$ & 204 & 192 & 396 & \multirow{4}{*}{0.231} \\
\hline Mean & 47.4 & 44.3 & 45.9 & \\
\hline $\mathrm{SD}$ & 27.6 & 24.4 & 26.1 & \\
\hline Missing & 0 & 0 & 0 & \\
\hline Interview data & $\begin{array}{l}\text { Verum } \\
(n=209)\end{array}$ & $\begin{array}{l}\text { Sham } \\
(n=200)\end{array}$ & $\begin{array}{l}\text { Total } \\
(n=409)\end{array}$ & $p$-value \\
\hline \multicolumn{5}{|c|}{ Estimated length of sessions (min) } \\
\hline$n$ & 204 & 191 & 395 & \multirow{4}{*}{0.718} \\
\hline Mean & 32.5 & 32.2 & 32.4 & \\
\hline SD & 7.5 & 8.8 & 8.1 & \\
\hline Missing & 5 & 9 & 14 & \\
\hline \multicolumn{5}{|c|}{$\begin{array}{l}\text { Estimated time physician } \\
\text { spent with the patient (min) }\end{array}$} \\
\hline$n$ & 204 & 191 & 395 & \multirow{4}{*}{0.045} \\
\hline Mean & 8.8 & 7.8 & 8.3 & \\
\hline SD & 5.4 & 4.8 & 5.1 & \\
\hline Missing & 5 & 9 & 14 & \\
\hline
\end{tabular}

*Not included in the calculation are the following cases (n): change of therapy (1), no therapy including dropouts prior to commencement of therapy (6), missing pages of CRF (6) 
pret: true acupuncture was superior to sham for most outcomes, although not for the pre-specified primary endpoint. The most informative comparison is between the results of the primary outcome, which defined response in terms of improvements both in headache and medication use, and the more traditional IHS endpoint, which depends only on headache response. The response rates for the primary and secondary endpoints for verum $v s$. sham acupuncture are, respectively, $33 \%$ and $66 \%$ vs. $27 \%$ and $55 \%$. Thus half of the patients in each group classified as responders by IHS criteria were classified as nonresponders using the study criteria due to changes in medication and so on. As such, the relative risk of response is the same for both endpoints $(\sim 0.8)$ but the risk difference is smaller for our primary endpoint because the event rate is lower. In other words, the apparently discrepant results of the primary and secondary analyses may simply be due to the reduced power of the primary analysis, resulting from more stringent response criteria and thus fewer events.

One explanation for the possible superiority of verum compared to sham acupuncture could be specific effects achieved by elicitation of "De Qi", another needling of points on the head (the site of pain), neither of which occur in the sham treatment. If "De Qi" represents a stimulation of afferent nerves, the physiological effect may be to release a cascade of endorphins and neurotransmitters [7]. Needling the site of pain (locus dolendi) may better adhere to the traditional Chinese concepts of acupuncture, but may also be a more potent placebo than needling points far away from the regions of pain.

Nevertheless, the response in the sham group appears unusually large for a 'placebo' arm in a randomised trial. In similar trials of non-acupuncture interventions for TTH, headache decreased in the placebo group by approximately $10 \%$ [19], 20\% [20] and <5\% [21] compared to approximately $50 \%$ in the current trial. There are several possible explanations for this effect. Firstly, sham acupuncture may have a stronger psychological effect than the dummy pill typically used as placebo control in drug trials. Along with other groups [22-24], we have observed that both acupuncture forms are invasive treatments. Invasive treatment techniques are almost always perceived by patients as profoundly meaningful, and such a strong "meaning response" [25] could contribute to symptom reduction [26, 27]. Indeed, Kaptchuk et al. have directly compared placebo pills and sham acupuncture in a randomised trial and found the latter to be more effective [27]. It may also be that our sham technique has physiologic activity. Although we inserted needles only superficially, in contrast to the deeper needling common in traditional Chinese acupuncture, some acupuncturists, such as those from the Japanese tradition [28], believe that superficial needle insertion is adequate to achieve clinical effectiveness and therefore insert needles only a few millimetres into the skin in routine clinical practice.

Several previous randomised trials have investigated whether acupuncture is of benefit for TTH. The largest of

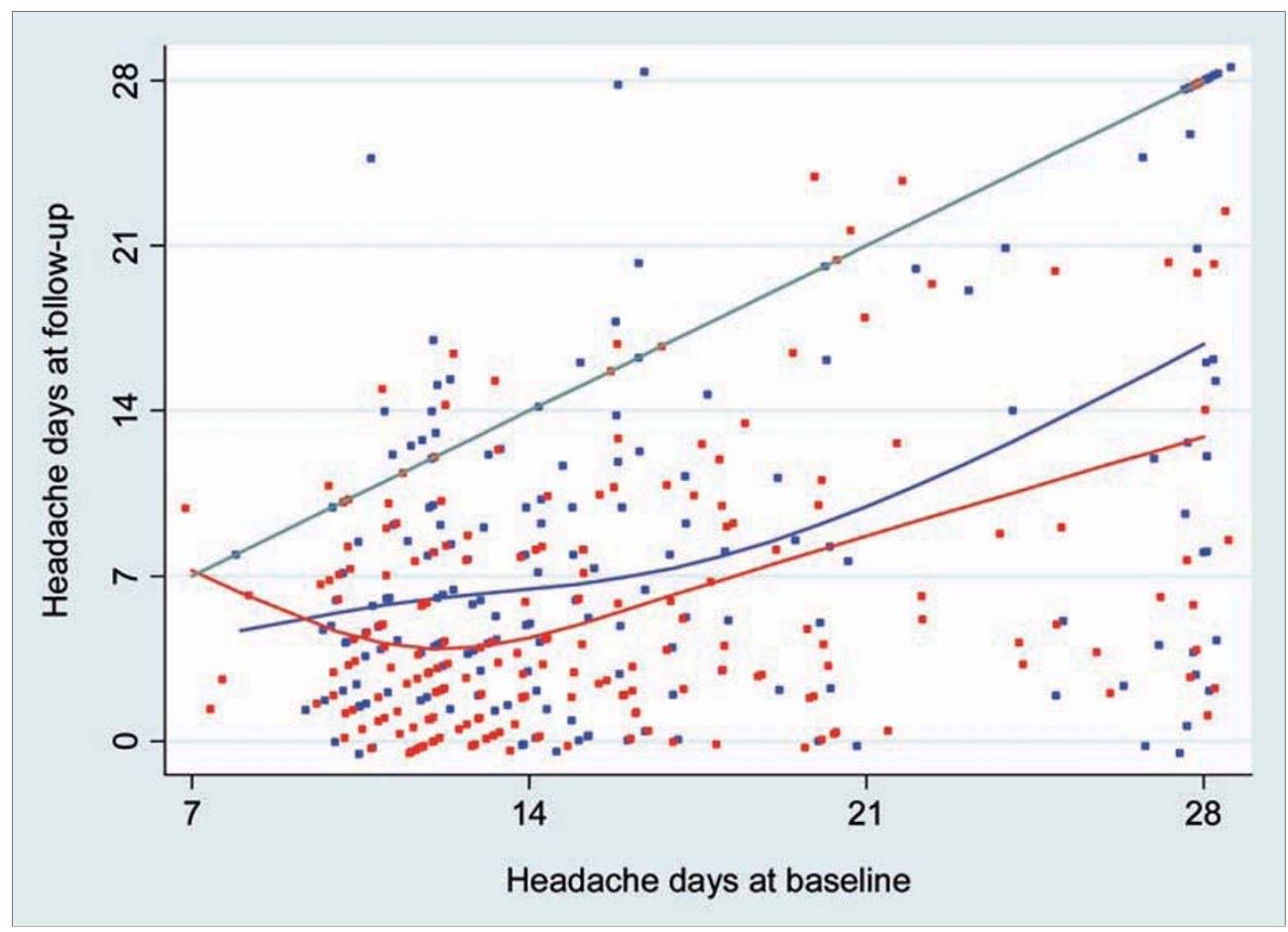

Fig. 3 Frequency of headache at baseline and at six months. Red squares are actual values for patients in the acupuncture group; blue squares are for controls. "Jitter" has been added to the points so that they do not overlap. The straight black line represents no change. The curved lines are regression lines (lower red line for acupuncture, upper blue line for control) 
these, which compared 132 verum patients with 63 sham controls [29], reported smaller overall decreases in headache days per month with no statistically significant differences between groups ( $41 \%$ verum vs. $37 \%$ sham, $p=0.58$ compared to $62 \%$ verum $v s .50 \%$ sham, $p<0.001$ ). The results of the other large randomised trial for chronic headache cannot be directly compared with ours as headache days was not an endpoint; nonetheless, a statistically significant difference was reported between patients randomised to acupuncture plus specialist headache care compared to those receiving specialist headache care alone [23]. The results of the trials appear somewhat discordant: it is for future meta-analysts to determine the extent differences between the trials are greater than what would be expected by chance, indicating genuine heterogeneity in treatments or patients.

In summary, we found that acupuncture is a promising option for treatment of long-standing TTH. The improve-

Table 3 Pain and quality of life endpoints for the trial ${ }^{\mathrm{a}}$

\begin{tabular}{|c|c|c|c|c|c|c|c|c|c|c|c|}
\hline & Baseline & & 6 weeks & & & 3 months & & & 6 months & & \\
\hline & Verum & Sham & Verum & Sham & 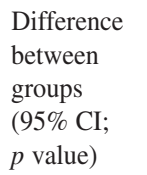 & Verum & Sham & 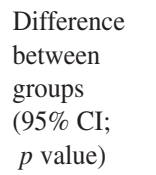 & Verum & Sham & 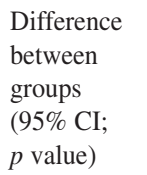 \\
\hline $\begin{array}{l}\text { Number } \\
\text { of patients }\end{array}$ & 209 & 200 & 209 & 200 & & 209 & 200 & & 209 & 200 & \\
\hline $\begin{array}{l}>50 \% \\
\text { reduction } \\
\text { of headache } \\
\text { days } / 4 \text { weeks }{ }^{b}\end{array}$ & & & $\begin{array}{l}138 / 204 \\
(68 \%)\end{array}$ & $\begin{array}{l}106 / 191 \\
(55 \%)\end{array}$ & $\begin{array}{l}12 \%[3 \% ; \\
22 \%] \\
p=0.013\end{array}$ & $\begin{array}{l}119 / 199 \\
(60 \%)\end{array}$ & $\begin{array}{l}91 / 192 \\
(47 \%)\end{array}$ & $\begin{array}{l}12 \%[3 \% ; \\
22 \%] \\
p=0.014\end{array}$ & $\begin{array}{l}135 / 204 \\
(66 \%)\end{array}$ & $\begin{array}{l}106 / 194 \\
(55 \%)\end{array}$ & $\begin{array}{l}12 \%[2 \% ; \\
21 \%] \\
p=0.024\end{array}$ \\
\hline $\begin{array}{l}\text { Headache } \\
\text { days/4 weeks }\end{array}$ & $\begin{array}{l}15.6 \\
(5.3)\end{array}$ & $\begin{array}{l}16.4 \\
(6.1)\end{array}$ & $\begin{array}{l}n=204, \\
6.2(6.7)\end{array}$ & $\begin{array}{l}n=191, \\
8.5(7.9)\end{array}$ & $\begin{array}{l}1.86[0.59 ; \\
3.14] \\
p=0.004\end{array}$ & $\begin{array}{l}n=199 \\
6.8(6.3)\end{array}$ & $\begin{array}{l}n=192, \\
9.1(8.0)\end{array}$ & $\begin{array}{l}1.80[0.58 \\
3.02] \\
p=0.004\end{array}$ & $\begin{array}{l}n=204, \\
6.0(6.2)\end{array}$ & $\begin{array}{l}n=194, \\
8.4(7.9)\end{array}$ & $\begin{array}{l}1.94[0.69 \\
3.18] \\
p=0.002\end{array}$ \\
\hline Pain intensity $^{\mathrm{c}}$ & $\begin{array}{l}68.3 \\
(12.1)\end{array}$ & $\begin{array}{l}67.5 \\
(12.5)\end{array}$ & & & & $\begin{array}{l}n=198, \\
57.6 \\
(17.2)\end{array}$ & $\begin{array}{l}n=191, \\
60.0 \\
(16.3)\end{array}$ & $\begin{array}{l}2.58[-0.75 \\
5.91] \\
p=0.13\end{array}$ & $\begin{array}{l}n=204, \\
53.5 \\
(18.4)\end{array}$ & $\begin{array}{l}n=194, \\
56.7 \\
(19.6)]\end{array}$ & $\begin{array}{l}3.24[-0.51 \\
6.99] \\
p=0.09\end{array}$ \\
\hline $\begin{array}{l}\text { Impairment } \\
\text { of activity }^{\mathrm{d}}\end{array}$ & $\begin{array}{l}n=209, \\
43.2 \\
(20.8)\end{array}$ & $\begin{array}{l}n=199, \\
43.3 \\
(20.1)\end{array}$ & & & & $\begin{array}{l}n=199, \\
25.0 \\
(21.1)\end{array}$ & $\begin{array}{l}n=190, \\
30.7 \\
(24.0)\end{array}$ & $\begin{array}{l}5.72[1.22 ; \\
10.2] \\
p=0.01\end{array}$ & $\begin{array}{l}n=202, \\
22.2 \\
(20.8)\end{array}$ & $\begin{array}{l}n=193, \\
26.7 \\
(24.7)\end{array}$ & $\begin{array}{l}4.54[0.03 ; \\
9.05] \\
p=0.049\end{array}$ \\
\hline $\begin{array}{l}\text { Quality of Life, } \\
\text { SF-12 (Physical } \\
\text { component } \\
\text { summary) }\end{array}$ & $\begin{array}{l}39.6 \\
(8.1)\end{array}$ & $\begin{array}{l}41.8 \\
(8.1)\end{array}$ & & & & $\begin{array}{l}n=199 \\
46.8 \\
(8.1)\end{array}$ & $\begin{array}{l}n=188 \\
46.5 \\
(8.3)\end{array}$ & $\begin{array}{l}1.06[-0.45 ; \\
2.57] \\
p=0.17\end{array}$ & $\begin{array}{l}n=204, \\
47.1 \\
(8.1)\end{array}$ & $\begin{array}{l}n=193 \\
46.5 \\
(8.6)\end{array}$ & $\begin{array}{l}1.38[-0.17 ; \\
2.92] \\
p=0.08\end{array}$ \\
\hline $\begin{array}{l}\text { Quality of Life, } \\
\text { SF-12 (Mental } \\
\text { component } \\
\text { summary) }\end{array}$ & $\begin{array}{l}45.9 \\
(10.3)\end{array}$ & $\begin{array}{l}46.1 \\
(10.1)\end{array}$ & & & & $\begin{array}{l}n=199 \\
50.0 \\
(9.1)\end{array}$ & $\begin{array}{l}n=188 \\
50.2 \\
(9.0)\end{array}$ & $\begin{array}{l}-0.10[-1.65 ; \\
1.46] \\
p=0.90\end{array}$ & $\begin{array}{l}n=204, \\
50.6 \\
(8.4)\end{array}$ & $\begin{array}{l}n=193 \\
50.8 \\
(9.2)\end{array}$ & $\begin{array}{l}0.05[-1.48 ; \\
1.58] \\
p=0.95\end{array}$ \\
\hline $\begin{array}{l}\text { Global patient } \\
\text { assessment }^{\mathrm{f}}\end{array}$ & & & $\begin{array}{l}2.6 \\
(1.2)\end{array}$ & $\begin{array}{l}3.0 \\
(1.5)\end{array}$ & $\begin{array}{l}0.4[0.1 ; \\
0.6] \\
p=0.005\end{array}$ & $\begin{array}{l}n=201, \\
2.6(1.2)\end{array}$ & $\begin{array}{l}n=192, \\
3.1(1.5)\end{array}$ & $\begin{array}{l}0.22[0.008 ; \\
0.43] \\
p=0.042\end{array}$ & $\begin{array}{l}n=204, \\
2.5(1.2)\end{array}$ & $\begin{array}{l}n=194, \\
3.0(1.5)\end{array}$ & $\begin{array}{l}0.30[0.08 \\
0.53] \\
p=0.009\end{array}$ \\
\hline \multicolumn{2}{|c|}{$\begin{array}{l}\text { Treatment } \\
\text { success }(\text { Global } \\
\text { patient assessment })^{\mathrm{f}}\end{array}$} & & $\begin{array}{l}163 \\
(82 \%)\end{array}$ & $\begin{array}{l}131 \\
(69 \%)\end{array}$ & $\begin{array}{l}12 \%[3.7 \% ; \\
21 \%]\end{array}$ & $\begin{array}{l}164 \\
(82 \%) \\
p=0.007\end{array}$ & $\begin{array}{l}122 \\
(64 \%)\end{array}$ & $\begin{array}{l}18 \%[9.0 \% ; \\
26 \%]\end{array}$ & $\begin{array}{l}164 \\
(81 \%) \\
p<0.001\end{array}$ & $\begin{array}{l}128 \\
(67 \%)\end{array}$ & $\begin{array}{l}14 \%[5.5 \% ; \\
23 \%] \\
\quad p=0.002\end{array}$ \\
\hline
\end{tabular}

${ }^{a}$ Data are mean (SD) or number (\%); 95\% CI, 95\% confidence interval; b headache days as defined in the inclusion criteria; ${ }^{c}$ von Korff (questions $1-3$ ) pain intensity score 0-100 (low values better); ${ }^{\mathrm{d}}$ von Korff (questions 5-7) impairment of activity score 0-100 (low values better); ${ }^{\mathrm{e}} \mathrm{SF} 12$ (high values better); ${ }^{\mathrm{f}}$ the number grading system used at German schools and universities consists of a six-point scale in which 1=very good, 2=good, 3=satisfactory, 4=adequate, 5=deficient, $6=$ inadequate: based upon that, the definition of treatment success is as follows: YES="very good", "good" or "satisfactory" 
Table 4 Medication use

\begin{tabular}{|c|c|c|c|c|c|}
\hline & \multicolumn{2}{|l|}{ Baseline } & \multicolumn{2}{|l|}{6 months } & \multirow{2}{*}{$\begin{array}{l}\text { Risk difference between } \\
\text { group proportions }[95 \% \mathrm{CI}]^{\mathrm{a}}\end{array}$} \\
\hline & Verum & Sham & Verum & Sham & \\
\hline & 209 & 200 & 209 & 200 & \\
\hline Patients with no medication use & $25(12 \%)$ & $34(17 \%)$ & $53(25 \%)$ & $51(26 \%)$ & $-0.1 \% \quad[-8.6 \% ; 8.3 \%] p=1$ \\
\hline Patients taking 1 medication & $116(56 \%)$ & $117(59 \%)$ & $114(55 \%)$ & $109(55 \%)$ & $0.0 \%[-9.7 \% ; 9.6 \%] p=1$ \\
\hline Patients taking more than 1 medication & $68(33 \%)$ & $49(25 \%)$ & $37(18 \%)$ & $34(17 \%)$ & $-0.7 \%[-8.0 \% ; 6.6 \%] p=0.9$ \\
\hline$>15$ days with medication & $19(9 \%)$ & $19(10 \%)$ & $2(1 \%)$ & $3(2 \%)$ & $0.5 \%[-1.6 \% ; 2.7 \%] p=0.8$ \\
\hline
\end{tabular}

${ }^{\mathrm{a}} 95 \% \mathrm{CI}, 95 \%$ confidence interval

Table 5 Categorisation of patients as responders and non-responders

\begin{tabular}{|c|c|c|}
\hline Patient category & Verum & Sham \\
\hline Total & 209 & 200 \\
\hline $\begin{array}{l}\text { Decrease in headache days } \leq 50 \% \\
\text { or less }\end{array}$ & $74(35 \%)$ & $94(47 \%)$ \\
\hline Decrease in headache days $>50 \%$ & $135(65 \%)$ & $106(53 \%)$ \\
\hline $\begin{array}{l}\text { Decrease in headache days }>50 \% \text {, } \\
\text { responder }\end{array}$ & $68(50 \%)$ & $53(50 \%)$ \\
\hline $\begin{array}{l}\text { Decrease in headache days }>50 \% \\
\text { but non-responder }\end{array}$ & $67(50 \%)$ & $53(50 \%)$ \\
\hline Change in medication use & 46 & 35 \\
\hline $\begin{array}{l}\text { Use of non-pharmacologic } \\
\text { concomitant therapy }\end{array}$ & 20 & 9 \\
\hline Unblinding & 12 & 11 \\
\hline Treatment protocol violations & 8 & 10 \\
\hline Change in medication use & 46 & 35 \\
\hline New cortisone therapy & 4 & 2 \\
\hline Disallowed concomitant medication & 14 & 13 \\
\hline $\begin{array}{l}\text { Change of allowed concomitant } \\
\text { medication }\end{array}$ & 12 & 7 \\
\hline $\begin{array}{l}\text { More than one allowed concomitant } \\
\text { medication }\end{array}$ & 19 & 20 \\
\hline Disallowed injections & 0 & 0 \\
\hline
\end{tabular}

Data are number (\%)

ments of all primary and secondary outcome measures were clinically significant and lasted long after completion of treatment. However, the mechanism of these effects is open to question. In particular, the degree to which treatment benefits depend on psychological compared to physiological effects and the degree to which any physiological effects depend on needle placement and insertion depth are unclear.
Table 6 Overview of the course of the study

\begin{tabular}{lll}
\hline Events & Verum & Sham \\
\hline Randomised & 209 & 200 \\
Treatment commenced & 208 & 195 \\
Treatment at least until extension interview & 204 & 192 \\
6 month interview conducted & 204 & 194 \\
Analysed in accordance with ITT & 209 & 200 \\
Therapy failures (multiple answers possible) & 141 & 147 \\
$\begin{array}{l}\text { amongst others: <50\% reduction, disallowed } \\
\text { concomitant therapies, premature cessation } \\
\text { of acupuncture treatment, etc. }\end{array}$ & \\
\begin{tabular}{l} 
Responders \\
\hline
\end{tabular} & 68 & 53 \\
\hline
\end{tabular}

Cessation of acupuncture treatment (fewer than 10 sessions) in a total of 19 patients (11 verum and 18 sham), but none of them due to adverse events

Acknowledgements We are grateful to the patients and colleagues in the participating centres involved in this project. We thank the staff of Winicker Norimed (Nuremberg) and of the Coordination Centers for Clinical Trials of the Universities of Duesseldorf, Heidelberg, Mainz and Marburg who contributed to monitoring and study management (http://www.kksnetzwerk.de). We would like to thank the members of the independent data and safety monitoring committee for their recommendations. The study was funded by the following German public health insurance companies: AOK, BKK, IKK, Bundesknappschaft, Bundesverband der Landwirtschaftlichen Krankenkassen and Seekasse. They did not influence study design, conduct of the study, data collection, management, analysis, interpretation of the data, manuscript preparation or publication decisions. 


\section{References}

1. Olesen J, Bousser M-G, Diener HC et al (2004) The International

Classification of Headache Disorders: 2nd edition. Cephalalgia, 24 [Suppl 1]: 9-160

2. Göbel H, Petersen-Braun M, Soyka D (1994) The epidemiology of headache in Germany: a nationwide survey of a representative sample on the basis of the headache classification of the International Headache Society. Cephalalgia 14:97-106

3. Rasmussen BK (2001) Epidemiology of headache. Cephalalgia 21:774-777

4. Schwartz BS, Stewart WF, Simon D, Lipton RB (1998) Epidemiology of tension-type headache. JAMA 279:381-383

5. Thomas KJ, Nicholl JP, Fall M (2001) Access to complementary medicine via general practice. Br J Gen Pract 51:25-30

6. Wadlow G, Peringer E (1996) Retrospective survey of patients of practitioners of traditional Chinese acupuncture in the UK. Complement Ther Med 4:1-7

7. Ezzo J, Berman B, Hadhazy VA, Jadad AR, Lao L, Singh BB (2000) Is acupuncture effective for the treatment of chronic pain? A systematic review. Pain 86:217-225

8. Melchart D, Linde K, Fischer P et al (2001) Acupuncture for idiopathic headache. Cochrane database of systematic reviews (Online), (1):CD001218

9. Endres HG, Zenz M, Schaub C et al (2005) Zur Problematik von Akupunkturstudien am Beispiel der Methodik von gerac. Schmerz 19:201-204, 206, 208-210 passim

10. Diener HC (2004) Advances in the field of headache 2003/2004. Curr Opin Neurol 17:271-273

11. Anonymous (1998) NIH Consensus Conference. Acupuncture. JAMA 280:1518-1524
12. Molsberger AF, Boewing G, Diener $\mathrm{HC}$ et al (2006) Designing an acupuncture study: the nationwide, randomized, controlled, german acupuncture trials on migraine and tension-type headache. J Altern Complement Med. New York, NY 12:237-245

13. Elliott AM, Smith BH, Smith WC, Chambers WA (2000) Changes in chronic pain severity over time: the Chronic Pain Grade as a valid measure. Pain 88:303-308

14. Von Korff M, Ormel J, Keefe FJ, Dworkin SF (1992) Grading the severity of chronic pain. Pain 50:133-149

15. Smith BH, Penny KI, Purves AM et al (1997) The Chronic Pain Grade questionnaire: validation and reliability in postal research. Pain 71:141-147

16. Ware J, Jr., Kosinski M, Keller SD (1996) A 12-Item Short-Form Health Survey: construction of scales and preliminary tests of reliability and validity. Medical care 34:220-233

17. Collins SL, Edwards J, Moore RA, Smith LA, McQuay HJ (2001) Seeking a simple measure of analgesia for mega-trials: is a single global assessment good enough? Pain 91:189-194

18. Endres HG, Molsberger A, Lungenhausen M, Trampisch HJ (2004) An internal standard for verifying the accuracy of serious adverse event reporting: the example of an acupuncture study of 190,924 patients. Eur J Med Res 9:545-551

19. Schulte-Mattler WJ, Krack P (2004) Treatment of chronic tension-type headache with botulinum toxin A: a randomized, double-blind, placebocontrolled multicenter study. Pain 109:110-114

20. Saper JR, Lake AE, $3^{\text {rd }}$, Cantrell DT, Winner PK, White JR (2002) Chronic daily headache prophylaxis with tizanidine: a double-blind, placebo-controlled, multicenter outcome study. Headache 42:470-482
21. Holroyd KA, O'Donnell FJ, Stensland M, Lipchik GL, Cordingley GE, Carlson BW (2001). Management of chronic tension-type headache with tricyclic antidepressant medication, stress management therapy, and their combination: a randomized controlled trial. JAMA 285:2208-2215

22. Diener HC, Kronfeld K, Boewing G et al (2006) Efficacy of acupuncture for the prophylaxis of migraine: a multicentre randomised controlled clinical trial. Lancet Neurol 5:310-316

23. Coeytaux RR, Kaufman JS, Kaptchuk $\mathrm{TJ}$ et al (2005) A randomized, controlled trial of acupuncture for chronic daily headache. Headache 45:1113-1123

24. Vickers AJ, Rees RW, Zollman CE et al (2004) Acupuncture for chronic headache in primary care: large, pragmatic, randomised trial. Br Med J 328:744-749

25. Moerman DE, Jonas WB (2002) Deconstructing the Placebo Effect and Finding the Meaning Response. Ann Intern Med 136:471-476

26. Kaptchuk TJ, Goldman P, Stone DA, Stason WB (2000) Do medical devices have enhanced placebo effects? J Clin Epidemiol 53:786-792

27. Kaptchuk TJ, Stason WB, Davis RB et al (2006) Sham device v inert pill: randomised controlled trial of two placebo treatments. Br Med J (Clinical research ed, 332:391-397

28. Birch S, Jamison RN (1998) Controlled trial of Japanese acupuncture for chronic myofascial neck pain: assessment of specific and nonspecific effects of treatment. Clin J Pain 14:248-255

29. Melchart D, Streng A, Hoppe A et al (2005) Acupuncture in patients with tension-type headache: randomised controlled trial. Br Med J (Clinical research ed 331:376-382 